\title{
Deriving an 0ptimal Restaurant Coupon Discount Rate: Evidence and Discussion
}

\author{
Tin-Chun Lin \\ School of Business and Economics, Indiana University-Northwest, Gary, IN, USA \\ Email: tinlin@iun.edu
}

How to cite this paper: Lin, T.-C. (2018) Deriving an Optimal Restaurant Coupon Discount Rate: Evidence and Discussion. Theoretical Economics Letters, 8, 1674-1683. https://doi.org/10.4236/tel.2018.810108

Received: April 23, 2018

Accepted: June 16, 2018

Published: June 19, 2018

Copyright $\odot 2018$ by author and Scientific Research Publishing Inc. This work is licensed under the Creative Commons Attribution International License (CC BY 4.0).

http://creativecommons.org/licenses/by/4.0/

\begin{abstract}
The model of third-degree price discrimination was used to derive the optimal coupon discount rate. Results showed that the optimal discount rate is related to the price elasticity of demand for restaurant sales in the market that do not involve coupons (the first market) and in the market with coupons (the second market). In light of the theoretical and data evidence, we also found that the price elasticity of demand for restaurant sales in both markets (with and without coupons) is elastic, and greater in the second market (with coupons) than in the first market (without coupons).
\end{abstract}

\section{Keywords}

Optimal Coupon Discount Rate, Price Elasticity of Demand, Restaurant Industry

\section{Introduction}

Empirical evidence [1] [2] has demonstrated that coupons are an effective marketing strategy in attracting new customers and retaining existing customers. This finding implies that giving customers' coupons not only can save customers a few dollars but also can enlarge business sales due to an increase in consumption and demand.

Identifying ways to determine an optimal restaurant coupon discount rate is important not only to attracting new customers and retaining existing customers but also to enlarging restaurant sales. In designing and preparing for this study, we did not immediately find a literature on ways to derive an algorithm for the optimal restaurant coupon discount rate. Although Lin [3] has provided a simple algorithm for coupon discount rate (i.e., $\delta=\tau+t+\tau t$, where $\delta=$ coupon discount rate; $\tau=$ sales tax rate; and $t=$ tipping rate), his simple algorithm is completely buyer-based and ignores the seller. Sellers who offer coupons to custom- 
ers increase their costs; it is possible that coupons may create losses for their business.

Therefore, in this paper we will use the model of third-degree price discrimination to derive an algorithm for the optimal restaurant coupon discount rate, which is the main contribution of the paper to the literature. In addition, based upon the optimal coupon discount rate, we will discuss the determinants of the optimal coupon discount rate and propositions stemming from this rate.

\section{The Optimal Coupon Discount Rate}

Consider a restaurant owner who randomly issues coupons to customers, so that customers are automatically split into two groups: 1) customers without coupons; and 2) customers with coupons. Certainly, customers without coupons will pay full price (a higher price), while customers with coupons will pay a discounted price (a lower price). Assume that the full price of one meal is $P_{1}$, while the discount price of one meal is $P_{2}$. Let $t$ be the coupon discount rate. Thus, $P_{2}=P_{1}(1-t)$. Suppose that the total number of meals consumed by customers without coupons is $Q_{1}$, while the total number of meals consumed by customers with coupons is $Q_{2}$. Hence, the total number of meals consumed by all customers is $Q_{T}=Q_{1}+Q_{2}$. In addition, the total cost of producing total meals is $C\left(Q_{T}\right)$. Total profit $(\pi)$ is then:

$$
\pi=P_{1} Q_{1}+P_{2} Q_{2}-C\left(Q_{T}\right) .
$$

The restaurant's objective is to maximize its profit. That is, the restaurant should increase its sales to each group of customers, $Q_{1}$ and $Q_{2}$ until the incremental profit from the last unit sold is zero. We set incremental profit for sales to the first group of customers (without coupons) equal to zero:

$$
\begin{aligned}
\frac{\partial \pi}{\partial Q_{1}} & =\frac{\partial\left(P_{1} Q_{1}\right)}{\partial Q_{1}}-\frac{\partial C}{\partial Q_{1}}=0 \\
& \Rightarrow \frac{\partial\left(P_{1} Q_{1}\right)}{\partial Q_{1}}=\frac{\partial C}{\partial Q_{1}} \\
& \Rightarrow M R_{1}=M C
\end{aligned}
$$

Similarly, for the second group of customers, we must also have:

$$
M R_{2}=M C
$$

Based upon Equations (2) and (3), we can find that prices and output must be set so that

$$
M R_{1}=M R_{2}=M C
$$

$$
\text { Note } M R_{1}=P_{1}\left(1-\frac{1}{\left|E_{1}^{d}\right|}\right)=P_{1}\left(1-\frac{1}{e_{1}}\right) \text { and } M R_{2}=P_{2}\left(1-\frac{1}{\left|E_{2}^{d}\right|}\right)=P_{1}\left(1-\frac{1}{e_{2}}\right) \text {, }
$$

where $E_{1}^{d}$ and $E_{2}^{d}$ are price elasticity of demand for the restaurant's sale in the first and second markets, respectively, and $\left|E_{1}^{d}\right|=e_{1} ;\left|E_{2}^{d}\right|=e_{2}$. Now equating $M R_{1}$ and $M R_{2}$ as in Equation (4) gives us the following relationship that must hold for prices: 


$$
\begin{gathered}
P_{1}\left(1-\frac{1}{e_{1}}\right)=P_{2}\left(1-\frac{1}{e_{2}}\right) \\
\Rightarrow \frac{P_{2}}{P_{1}}=\frac{1-\frac{1}{e_{1}}}{1-\frac{1}{e_{2}}} .
\end{gathered}
$$

Since $P_{2}=P_{1}(1-t)$,

$$
\frac{P_{2}}{P_{1}}=1-t=\frac{1-\frac{1}{e_{1}}}{1-\frac{1}{e_{2}}} .
$$

According to Equation (6), we can solve the optimal coupon discount rate $\left(t^{*}\right)$, which is shown below:

$$
t^{*}=\frac{e_{2}-e_{1}}{\left(e_{2}-1\right) e_{1}} .
$$

Equation (7) shows that the optimal coupon discount rate $\left(t^{*}\right)$ is related to the price elasticity of demand for restaurant sales in the first and second markets.

\section{Proposition 1:}

Restaurant owners would be willing to continue issuing coupons to customers only when the price elasticity of demand for the restaurant's sales in the second market $\left(e_{2}\right)$ is elastic (i.e., $\left.e_{2}>1\right)$, and the price elasticity of demand for the restaurant's sales is larger in the second market than in the first market $\left(e_{1}\right)$ (i.e., $\left.e_{2}>e_{1}\right)$.

\section{Proof:}

According to Equation (7), if $e_{2} \leq e_{1}$, the coupon discount rate $(t)$ will become zero or negative. In addition, if the price elasticity of demand for the restaurant's sale in the second market $\left(e_{2}\right)$ is inelastic (i.e., $\left.e_{2}<1\right)$ or unit elastic (i.e., $e_{2}=1$ ), the coupon discount rate $(t)$ will become zero or infinite. If the coupon discount rate $(t)$ is zero, it is not necessary to issue coupons to customers. Moreover, it does not make any sense to set a negative or infinite discount rate for coupons. Q. E. D.

Proposition 1 implies that coupons promote restaurants' sales only when those customers who used coupons become more sensitive to the price change than those customers who did not have coupons (i.e., $e_{2}>e_{1}$ and $e_{2}>1$ ). When those customers become more sensitive to the price change, they are more willing to revisit the same restaurant more frequently due to the availability of coupons and the prospect of paying a lower price.

It should be noted that although both $e_{2}<e_{1}$ and $e_{2}<1$ co-exist at the same time in the market, resulting in a positive coupon discount rate (shown in Equation (7)), there is no economic meaning in reality for the following two reasons:

1) If the price elasticity of demand for restaurant sales in the second market 
$\left(e_{2}\right)$ is inelastic (i.e., $\left.e_{2}<1\right)$, then those customers in the second market are not sensitive to price change. The discount price would not significantly increase demand for restaurant meals. In other words, customers would not really indicate appreciation for the coupon promotion by increasing demand for meals. In addition (and more importantly), when market demand is inelastic, a lower price will lead to a decrease in total revenue-restaurant owners may lose their money by issuing coupons.

2) If customers who have coupons are even less sensitive to a price change than customers who never have coupons, then why would restaurant owners want to continue issuing coupons to customers in the second market? If offering coupons does not significantly increase sales in the second market (perhaps even leading to lost revenue due to increased costs), restaurant owners have no incentive to continue issuing coupons to customers in the second market.

\section{Proposition 2:}

When the price elasticity of demand for restaurant sales in the first market $\left(e_{1}\right)$ is elastic (i.e., $\left.e_{1}>1\right)$, restaurant owners definitely have no incentive to issue coupons that offer completely free meals.

\section{Proof:}

Not offering completely free meals means that the coupon discount rate $(t)$ must be less than 1 . Therefore:

$$
\begin{gathered}
t^{*}=\frac{e_{2}-e_{1}}{\left(e_{2}-1\right) e_{1}}<1 \\
\Rightarrow e_{2}-e_{1}<\left(e_{2}-1\right) e_{1} \\
\Rightarrow e_{2}-e_{1}<e_{1} e_{2}-e_{1} \\
\Rightarrow e_{1}>1 .
\end{gathered}
$$

\section{Q. E. D.}

Proposition 2 implies that the restaurant food market is quite competitive. Even though customers who do not have coupons are also sensitive to the price changes (i.e., the price elasticity of demand for a restaurant's sales in the first market $\left(e_{1}\right)$ is elastic), even a small percentage discount in price would result in a large percentage increase in quantity demanded for restaurant food meals. For that reason, restaurant owners definitely do not have any incentive to issue coupons that offer customers completely free meals.

\section{Proposition 3:}

It is necessary for restaurant owners to issue coupons to customers only when the price elasticity of demand for the restaurant's sale in the market is elastic (i.e., $e>1$ ), both in the first and the second market (i.e., $e_{1}>1$ and $e_{2}>1$ ).

\section{Proof:}

Based upon Propositions 1 - 2, the price elasticity of demand for restaurant sales in both the first and the second market has to be elastic (i.e., $e_{1}>1$ and $e_{2}>1$ ). Only when they are elastic will a discount price increase total sales (total revenues). Q. E. D. 


\section{Comparative Static Analysis}

We further show a comparative static analysis by taking first derivatives with respect to $e_{1}$ and $e_{2}$, which yield:

$$
\begin{aligned}
& \frac{\partial t^{*}}{\partial e_{1}}=\frac{e_{2}\left(e_{2}-1\right)}{\left(e_{1} e_{2}-e_{1}\right)^{2}} \\
& \frac{\partial t^{*}}{\partial e_{2}}=\frac{e_{1}\left(e_{1}-1\right)}{\left(e_{1} e_{2}-e_{1}\right)^{2}}
\end{aligned}
$$

\section{Proposition 4(a):}

If consumers in the second market are sensitive to price changes (i.e., the price elasticity of demand for restaurant sales in the second market $\left(e_{2}\right)$ is elastic (i.e., $\left.e_{2}>1\right)$, the price elasticity of demand for restaurant sales in the first market $\left(e_{1}\right)$ and restaurant discount rate $(t)$ will be positively related. That is, the larger the price elasticity of demand for the restaurant's sales in the first market, the greater will be the coupon discount rate.

Proof:

According to Equation (8), if $e_{2}>1$, then $\frac{\partial t^{*}}{\partial e_{1}}=\frac{e_{2}\left(e_{2}-1\right)}{\left(e_{1} e_{2}-e_{1}\right)^{2}}>0$. Q. E. D.

\section{Proposition 4(b):}

If consumers in the second market are not sensitive to price changes (i.e., the price elasticity of demand for restaurant sales in the second market $\left(e_{2}\right)$ is inelastic (i.e., $e_{2}<1$ ), the price elasticity of demand for restaurant sales in the first market $\left(e_{1}\right)$ and restaurant discount rate $(t)$ will be negatively related. That is, the larger the price elasticity of demand for restaurant sales in the first market, the lower will be the coupon discount rate.

Proof:

According to Equation (8), if $e_{2}<1$, then $\frac{\partial t^{*}}{\partial e_{1}}=\frac{e_{2}\left(e_{2}-1\right)}{\left(e_{1} e_{2}-e_{1}\right)^{2}}<0$. Q. E. D.

\section{Proposition 4(c):}

If the price elasticity of demand for restaurant sales in the second market $\left(e_{2}\right)$ is unit elastic (i.e., $e_{2}=1$ ), the price elasticity of demand for restaurant sales in the first market $\left(e_{1}\right)$ and restaurant discount rate $(t)$ will not be related. That is, the price elasticity of demand for restaurant sales in the first market will not influence the coupon discount rate.

Proof:

According to Equation (8), if $e_{2}=1$, then $\frac{\partial t^{*}}{\partial e_{1}}=\frac{e_{2}\left(e_{2}-1\right)}{\left(e_{1} e_{2}-e_{1}\right)^{2}}=0$. Q. E. D.

\section{Proposition 5(a):}

If consumers in the first market are sensitive to price changes (i.e., the price elasticity of demand for restaurant sales in the first market $\left(e_{1}\right)$ is elastic (i.e., $\left.e_{1}>1\right)$, the price elasticity of demand for restaurant sales in the second market $\left(e_{2}\right)$ and restaurant discount rate $(t)$ will be positively related. That is, the larger the price elasticity of demand for restaurant sales in the second market, the 
greater will be the coupon discount rate.

\section{Proof:}

According to Equation (9), if $e_{1}>1$, then $\frac{\partial t^{*}}{\partial e_{2}}=\frac{e_{1}\left(e_{1}-1\right)}{\left(e_{1} e_{2}-e_{1}\right)^{2}}>0$. Q. E. D.

\section{Proposition 5(b):}

If consumers in the first market are not sensitive to price changes (i.e., the price elasticity of demand for restaurant sales in the second market $\left(e_{1}\right)$ is inelastic (i.e., $\left.e_{1}<1\right)$, the price elasticity of demand for restaurant sales in the second market $\left(e_{2}\right)$ and restaurant discount rate $(t)$ will be negatively related. That is, the larger the price elasticity of demand for restaurant sales in the second market, the lower will be the coupon discount rate.

Proof:

According to Equation (9), if $e_{2}<1$, then $\frac{\partial t^{*}}{\partial e_{2}}=\frac{e_{1}\left(e_{1}-1\right)}{\left(e_{1} e_{2}-e_{1}\right)^{2}}<0$. Q. E. D.

\section{Proposition 5(c):}

If the price elasticity of demand for restaurant sales in the first market $\left(e_{1}\right)$ is unit elastic (i.e., $e_{1}=1$ ), the price elasticity of demand for restaurant sales in the second market $\left(e_{2}\right)$ and restaurant discount rate $(t)$ will not be related. That is, the price elasticity of demand for restaurant sales in the second market will not influence the coupon discount rate.

Proof:

According to Equation (9), if $e_{1}=1$, then $\frac{\partial t^{*}}{\partial e_{2}}=\frac{e_{1}\left(e_{1}-1\right)}{\left(e_{1} e_{2}-e_{1}\right)^{2}}=0$. Q. E. D.

\section{Data Evidence}

In November 2016, we informally interviewed the owner of a buffet restaurant (note: the restaurant owner was not comfortable with having his restaurant's name disclosed in our paper, so we cannot share that information), located in Indiana. The restaurant owner is a close friend of the authors. Therefore, he was very willing to share information with us, but he was not willing to share detailed information regarding restaurant sales due to confidentiality. Based upon the information he provided, we were able to identify some of the data evidence we needed. Below, we summarize the information he offered and how some of that data supported our theoretical evidence.

\section{Information 1}

In summer 2010, for business development reasons, the owner cut prices by $10 \%$. After instituting these price cuts, restaurant sales approximately increased $12 \%-15 \%$ on average the following full-year's sales compared with the previous full-year's sales without a price cut. With this information, we were able to estimate that the price elasticity of demand for restaurant sales is elastic and should be around 1.2 - 1.5. This is a buffet restaurant, so the price for each regular adult customer should be the same. That is, a $12 \%-15 \%$ increase in sales implies that the number of meals may also roughly increase by $12 \%-15 \%$. For that reason, 
we estimated that the price elasticity of demand was around $1.2-1.5$

$$
\left(=\left|\frac{\frac{\Delta Q}{Q}}{\frac{\Delta P}{P}}\right|=\left|\frac{12 \%}{-10 \%}\right| \sim\left|\frac{15 \%}{-10 \%}\right|\right) .
$$

Another reason for elastic demand is that the total sales increased when prices dropped, implying that the price elasticity of demand for the market must be elastic.

\section{Information 2}

In January 2014, the owner started randomly issuing 15\% discount rate coupons to customers in local areas. Thereafter, total sales roughly increased $20 \%$ $25 \%$ on average in following full-year sales compared with past-year sales without coupons. In addition, the owner said that about one-half of customers used coupons-most of these people were existing customers. With this information, we estimated that the price elasticity of demand for restaurant sales in the second market (with coupons) was elastic and was larger than $1.2-1.5$ for the following reason.

Suppose that everyone received the $15 \%$ discount-this would make the price elasticity of demand for restaurant sales in the market with coupons around 1.33 $-1.67$

$$
\left(=\left|\frac{20 \%}{-15 \%}\right| \sim\left|\frac{25 \%}{-15 \%}\right|\right) .
$$

Since only around $50 \%$ of customers used coupons, the 1.33 - 1.67 finding may reflect the mean of these two markets (with coupons and without coupons). We estimated that the price elasticity of demand for restaurant sales in the first market (without coupons) could be still around 1.2 - 1.5. For that reason, the price elasticity of demand for restaurant sales in the second market (with coupons) must be higher than $1.33-1.67$. Hence, we concluded that the price elasticity of demand for restaurant sales in the second market (with coupons) was elastic and larger than the price elasticity of demand in the first market (without coupons).

\section{Short Summary}

Based upon Information 1 and Information 2 and our estimations, we can briefly conclude that the price elasticity of demand for restaurant sales: 1) in the overall market is elastic; 2) in the coupon market is elastic; and 3) is larger in the coupon market than in the no-coupon market. Our data evidence is consistent with our theoretical evidence (shown in Propositions 1 - 3).

\section{Discussion}

In this paper, we used the model of third-degree price discrimination to derive the optimal coupon discount rate. However, the case of coupons differs somewhat from the traditional case of third-degree price discrimination, such as, say, movie tickets-where the price of a movie ticket for children is cheaper than the 
price of a movie ticket for adults. In the movie market, for example, two markets (children and adults) existed before the theater separated these two groups into two markets, which means that the price elasticity of demand for movie sales in each market may be determined. Therefore, based upon the price elasticities of these two markets, the theater can determine prices for children and adults.

With regard to the restaurant market, before the restaurant owner randomly issues coupons to customers, the two markets (with coupons and without coupons) do not exist. For that reason, the restaurant owner is not able to figure out the price elasticity of demand for restaurant sales in each market. Hence, the question is: how can the restaurant owner determine the coupon discount rate initially when he/she is going to split the market into two markets? To answer this question, we have some strategy suggestions.

We suggest that restaurant owners may try a $15 \%$ discount rate first. Most customers normally tip around $15 \%$ of the total bill amount. That is, giving customers a $15 \%$ discount implies that restaurant owners bear the tipping cost for customers. Lin [4] verified that tips discourage consumers' demand for restaurant meals and create a deadweight loss in the restaurant food market. Thus, bearing the tipping cost would increase customers' demand for meals and avoid deadweight loss in the restaurant food market. Alternatively, restaurant owners may adopt Lin's [3] simple algorithm of coupon discount rate at the beginning. The idea of using this method to determine the coupon discount rate means that restaurant owners bear the costs (sales taxes and tips) for customers, so consumers who use coupons will only pay the initial price of the meal. If restaurant owners think that suggested coupon discount rates discussed above are too high and are not affordable, they may elect to try a $10 \%$ discount rate first. However, a discount rate below $10 \%$ (say $5 \%$ ) may not significantly attract customers since there is a less than remarkable difference between having coupons versus not having coupons.

No matter which strategy the restaurant owners choose, the main purpose is to divide the market into two markets. After the market is split into two markets (with coupon and without coupon) and a period of time, restaurant owners need to conduct a survey to investigate the price elasticity of demand for each market, and then plug them into Equation (7) to yield an optimal discount rate. We suggest that restaurant owners conduct regular investigations and, based on findings, adjust the coupon discount rate if necessary, because the price elasticity of demand may change over time.

In addition to the issue of how restaurant owners determine the coupon discount rate when they are going to split the market into two markets, another issue that needs to be discussed is: why is the price elasticity of demand for customers who used coupons higher than the price elasticity of demand for customers who did not use coupons? That is, why do customers become more sensitive to price change after they use coupons for a while? Below, we describe our possible explanation. 
When customers receive coupons, they feel that they are being promoted by paying less, and thus their utility is enhanced from the initial utility (say $U_{0}$ ) to a higher utility (say $U_{1}$ ). These customers will respond to this promotion by increasing their consumption demand. However, after they use coupons for a while, if restaurants stop issuing customers coupons, those customers who initially use coupons will feel that they are being demoted by paying more, and hence their utility would significantly drop from the higher utility $U_{1}$ to a lower utility (say $U_{-1}$ ), a utility that is even lower than the initial utility $U_{0}$-that is, before they initially received coupons. Customers will respond to this demotion by lowering their consumption to a level even lower than the initial level of consumption. As a result, customers who use coupons will become more sensitive to price change after they use coupons for a while. The price elasticity of demand for customers who used coupons becomes higher than the price elasticity of demand for customers who do not use coupons.

\section{Conclusions}

In this paper, we used the model of third-degree price discrimination to derive the optimal coupon discount rate. We found that the optimal discount rate is related to the price elasticity of demand for restaurant sales in the market without coupons (the first market) and the market with coupons (the second market).

In addition, in light of the theoretical and data evidence, we found that the price elasticity of demand for restaurant sales in both markets (with and without coupons) is elastic, and is larger in the second market (with coupons) than in the first market (without coupons). This finding is consistent with our initial prediction, because the restaurant industry engages in monopolistic competition. In the monopolistically competitive market, the market demand curve is flatter, implying that the price elasticity of demand is elastic.

Moreover, we discussed the ways in which the restaurant owner determines the coupon discount rate initially, when the restaurant splits the market into two markets. We suggested three strategies: 1 ) try a $15 \%$ discount rate; 2) adopt Lin's [3] simple algorithm for a coupon discount rate; or 3) try a $10 \%$ discount rate, but go no lower than $10 \%$ due to the unremarkable difference between coupons and no coupons at this rate.

Finally, this paper has one limitation. The main purpose of this paper was to theoretically derive an algorithm for the optimal restaurant coupon discount rate and discuss propositions. We did not plan to conduct an empirical analysis for this paper, thus only informally interviewed one restaurant owner, which could result in the sample selection bias problem. Therefore, in our future research plan, we will propose an empirical study based upon the theoretical analysis and formally interview a significant number of restaurant owners to collect data.

\section{Acknowledgements}

The author would like to thank Ms. Joy Deng for her editorial assistance and the 
anonymous referee for his/her feedback and suggestions.

\section{References}

[1] Qu, H. (1997) Determinant Factors and Choice Intention for Chinese Restaurant Dining: A Multivariate Approach. Journal of Restaurant and Foodservice Marketing, 2, 35-49. http://download.xuebalib.com/xuebalib.com.22812.pdf https://doi.org/10.1300/J061v02n02_03

[2] Chang, J. (2003) Analyzing the Impact of Sales Promotions on the Sources of Category Expansion. Northwestern University, ProQuest Dissertations Publishing, 1-446.

[3] Lin, T.-C. (2017) Modeling Consumer Intention to Revisit the Same Restaurant and a Simple Algorithm of Coupon Discount Rate. Theoretical Economics Letters, 7, 1179-1188. http://file.scirp.org/pdf/TEL_2017072014435686.pdf https://doi.org/10.4236/tel.2017.75079

[4] Lin, T.-C. (2015) Modeling the Relationship between Restaurant Tipping and Consumer Behavior. Theoretical Economics Letters, 5, 389-395.

http://file.scirp.org/pdf/TEL_2015052716150529.pdf

https://doi.org/10.4236/tel.2015.53044 